\title{
La descentralización universitaria en Uruguay. Los intentos de crear una universidad en Salto ${ }^{1}$
}

\author{
María Eugenia Jung \\ Área de Investigación Histórica \\ Archivo General de la \\ Universidad de la República (Uruguay) \\ mariaeugeniajung@gmail.com
}

\begin{abstract}
Resumen
El presente trabajo se propone analizar los orígenes en la ciudad de Salto de un amplio movimiento social local favorable a la creación de una universidad ubicada en esa región. En el imaginario local éste oficiaría como un elemento dinamizador del desarrollo integral y autónomo de la región. Por dicha razón, diversas organizaciones sociales, asociaciones de estudiantes, padres y docentes, con el apoyo de las autoridades municipales, iniciaron gestiones ante el gobierno nacional y universitario para conseguir el apoyo político y especialmente los recursos económicos que lo hicieran posible. El texto se concentra en dos momentos que marcaron el rumbo de este proyecto en las décadas siguientes: la colocación de la piedra fundamental de la Universidad del Norte en 1948 y la instalación en 1957 de cursos libres de primer y segundo año de derecho y notariado de la Universidad de la República. La suerte que corrieron estas iniciativas, que subsistieron en las décadas siguientes, demostró los escasos márgenes de maniobra que tenían los actores locales para hacerlos realidad. Su concreción dependía de lograr los apoyos políticos necesarios, especialmente, del gobierno central así como de la UDELAR; hasta el momento la única universidad que existía en Uruguay. Pese a la insistente presión local, la posibilidad de descentralizar la educación superior no se
\end{abstract}

1 Este trabajo forma parte de mi tesis de maestría "Educación superior y derecha Radical en Uruguay. La creación del Movimiento pro-Universidad del Norte en Salto (1968-1984)" que analiza a través del estudio de la singular trayectoria del Movimiento pro-Universidad del Norte, de sus ideas y bases de apoyo, el tipo de demandas y las formas de asociacionismo que sustentaron a algunos de los grupos de derecha de importante actividad en la época al tiempo que se incorporaban a los discusiones que, en los países latinoamericanos y en el mundo, se estaban procesando sobre la ciencia y la tecnología y el rol de las universidades para el desarrollo.. La directora de tesis es la Dra. Vania Markarian.

JUNG, María Eugenia, "La descentralización universitaria en Uruguay. Los intentos de crear una universidad en Salto", en Avances del Cesor, Año X, № 10, 2013, pp. 73-97. 
incorporó a la agenda pública ni formó parte de los principales debates universitarios hasta muy entrada la década del sesenta. Sin embargo, la presión ejercida ofició como un acicate para que la Universidad de la República se planteara con mayor énfasis incrementar su presencia en el interior del país.

Palabras clave: Universidad - Historia - Descentralización universitaria

\begin{abstract}
The purpose of this paper is to analyze the origins of a large local social movement in the city of Salto, propitious to the creation of a University located in that area. In the local imaginary this movement represents a revitalizing factor of integral and independent development of that area. For this reason, several social organizations, associations of students, parents and teachers, with the support of public authorities, have begun negotiations with both national government and University to get political support, especially financial resources to make it possible. The text focuses on two moments that set the course of this project in the subsequent decades: the placing of the cornerstone of the North University in 1948 and the implementation in 1957 of free courses for first and second year of Law from the Public University. The initiatives which subsisted in the following decades have demonstrated the limited room for movement that local actors had to accomplish them. Its concretion depended on achieving the necessary political support, especially from the central government, as well as from the UDELAR, the only University existing in Uruguay so far. Despite the persistent local pressure, the possibility of decentralizing the higher education was neither incorporated into the public agenda nor included into the main university discussions until the sixties. However, the pressure applied encouraged the Public University to arise with greater emphasis to increase its presence inside the country.
\end{abstract}

Key Words: University - History - University decentralization

\title{
Introducción
}

El presente trabajo se propone analizar los orígenes en la ciudad de Salto de un amplio movimiento social local favorable a la creación de una universidad ubicada en esa región. En el imaginario local éste oficiaría como un elemento dinamizador del desarrollo integral y autónomo de la región. Por dicha razón, diversas organizaciones sociales, asociaciones de estudiantes, padres y docentes, con el apoyo de las autoridades municipales, iniciaron gestiones ante el gobierno nacional y universitario para conseguir el apoyo político y especialmente los recursos económicos que lo hicieran posible. El texto se concentra en dos momentos que marcaron el rumbo de este proyecto en las décadas siguientes: la colocación de la piedra fundamental de la Universidad del Norte en 1948 y la instalación en 1957 de cursos libres de primer y segundo año de derecho y notariado de la Universidad 
de la República ${ }^{2}$. La suerte que corrieron estas iniciativas, que subsistieron en las décadas siguientes, demostró los escasos márgenes de maniobra que tenían los actores locales para hacerlos realidad. Su concreción dependía de lograr los apoyos políticos necesarios, especialmente, del gobierno central así como de la UDELAR; hasta el momento la única universidad que existía en Uruguay. Pese a la insistente presión local, la posibilidad de descentralizar la educación superior no se incorporó a la agenda pública ni formó parte de los principales debates universitarios hasta muy entrada la década del sesenta. Sin embargo, la presión ejercida ofició como un acicate para que la Universidad de la República se planteara con mayor énfasis incrementar su presencia en el interior del país. Por último, el artículo repasa muy brevemente el derrotero de esta iniciativa y del movimiento social que la sostuvo a finales del sesenta cuando Uruguay asistía a una grave crisis social, económica y política. El clima de radicalización que dominó esos años condicionó el giro hacia la derecha de parte de este movimiento.

\section{La descentralización universitaria: una vieja aspiración local}

Al promediar la década del cuarenta, la idea de crear una universidad en el interior del país recibió un fuerte impulso en varias ciudades del norte del Uruguay, entre ellas Paysandú y Salto. Las iniciativas al respecto, de fuerte impronta local, fueron promovidas por organizaciones civiles, asociaciones profesionales, agrupaciones de padres, docentes y estudiantes con el apoyo de las autoridades municipales. La confluencia de diversos sectores sociales y políticos condicionó que las propuestas originalmente se mantuvieran exentas de todo contenido político o vinculación con tendencia político-ideológica alguna. Los argumentos esgrimidos, de carácter reivindicativo, ponían el acento en los desequilibrios que en materia educativa existían entre Montevideo y el resto del país, reactualizando la tradicional dicotomía Montevideo-interior y las desigualdades existentes entre ambas regiones. En ámbitos locales, la lucha por descentralizar la educación superior se integraba a las demandas más generales de ampliar la autonomía político administrativa departamental respecto a la capital. Este sentimiento se manifestó con mayor fuerza en el norte uruguayo cuya configuración socio-económica e institucional así como su proceso de poblamiento y urbanización fue mucho más tardía generando fuertes desequilibrios con el resto del país. Tales asimetrías, seguramente, contribuyeron a que los norteños manifestaran precozmente una mayor rebeldía y un fuerte sentido autonómico ante el poder capitalino que se mantuvo a través de los años. En 1948, El Telégrafo de Paysandú se refería a la desigual relación Montevideo-Interior en términos de metrópoli/colonia afirmando que:

El centralismo, con tremenda obstinación, ha formado una metrópolis y una colonia que le es tributaria y toda su dinámica consiste en mantener y acrecentar el sometimiento

2 En adelante, UDELAR. 
de esta última y en dar a la primera grandeza y esplendor a expensas de la segunda. Por eso mientras en Montevideo se erige el gigantesco Hospital de Clínicas, no se inaugura ninguna sala de auxilios en las zonas rurales, donde la población paisana muere sin asistencia médica; por eso no se crean facultades ni universidades en el interior; por eso hace ya quince años que fue conculcada la autonomía municipal y aún no se ha conseguido se la restaure; por eso la administración pública adolece de absurda y prepotente centralización; por eso el desarrollo industrial de país, ha sido fomentado en base de protecciones y privilegios muchas veces desmesurados y nocivos, encaminados a producir la centralización de las industrias; por eso la campaña, aunque sufraga puntualmente, no puede jactarse de tener representantes y defensores auténticos en el Parlamento, salvo raras excepciones, pues los hombres que elige son movidos por la fuerza centrípeta de los partidos. ${ }^{3}$

En otro orden, en el contexto más general del Uruguay de la postguerra, signado por la prosperidad económica que se reflejó en la mejora de las condiciones de vida y el poder adquisitivo de vastos sectores de la sociedad, estas demandas expresaban las aspiraciones de las emergentes clases medias de esas mismas ciudades que vislumbraban en la enseñanza en general, $y$ en la superior en particular, un camino para alcanzar sus expectativas de ascenso social. Por esos años la educación secundaria comenzó a experimentar un crecimiento exponencial de su población así como la ampliación de sus bases sociales, situación que también tuvo su correlato en el interior del país. En diferentes localidades se crearon nuevas instituciones educativas que fueron fruto de la movilización de los propios residentes locales, "personas con destacadas y calificadas aspiraciones de crecimiento colectivo, profesionales e intelectuales que jugaron un papel fundamental". Quienes impulsaban estas iniciativas lo hacían, "con la razonable preocupación de que [sus hijos tuvieran] una preparación 'conveniente' para sustituir a sus padres en la dirección de empresas o comercios, o para habilitarlos para el traslado al gran mercado de empleo de terciarios que es Montevideo, y en casi todos los casos anhelando que el liceo sea una primera etapa hacia las carreras liberales". ${ }^{4}$ De estos mismos sectores partieron los planteos tendientes a crear centros de educación superior fuera de Montevideo.

En particular, los grupos locales fundamentaban la propuesta en las dificultades que numerosas familias debían enfrentar para costear el traslado y el mantenimiento de los estudios de sus hijos en la capital. Esta situación se agravaba en las localidades norte-

3 “El Interior sufre bajo la maldición del centralismo", El Telégrafo, Paysandú, 08/06/1948.

4 Germán Rama, Grupos Sociales y Enseñanza Secundaria, Arca, Montevideo, 1964, pp. 20-21. Rama señala que el crecimiento global de la población de secundaria en el Interior entre 1942-1960 fue superior a la de Montevideo. En el interior "es el resultado en su mayor parte de la extensión de la enseñanza secundaria a capas sociales medias y superiores en zonas carentes hasta ahora de centros secundarios, [en Montevideo] refleja una tendencia vertical, integrando hijos de hogares de baja clase media y de clase popular que hace 20 años no tenían otra meta que la realización del ciclo escolar". 
ñas debido a la gran distancia que las separaba de Montevideo. Se advertía, además, que aquellos que accedían a la enseñanza universitaria emigraban definitivamente propiciando la pérdida de recursos calificados. No es de extrañar entonces que desde esos ámbitos surgieran alternativas a este problema. Sin embargo, y pese a su cercanía, las propuestas que emergieron en ámbitos departamentales no fueron pensadas en términos de complementariedad regional sino que se concibieron en un marco de competencia por conseguir los apoyos centrales para sus propios proyectos locales.

La suerte que corrieron estos proyectos, que persistieron en las décadas siguientes, demostró los escasos márgenes de maniobra que tenían los actores locales para hacerlos realidad. Su concreción dependía de lograr los apoyos políticos necesarios, del gobierno central así como de la UDELAR ${ }^{5}$. Pese a la insistente presión local y a la amplia campaña desarrollada desde ámbitos locales la posibilidad de descentralizar la educación superior no se incorporó a la agenda pública ni formó parte de los principales debates universitarios hasta muy entrada la década del sesenta.

\section{Los intentos de fundar la Universidad del Norte en Salto (1948-1960)}

El Departamento de Salto está ubicado en la zona litoral de Uruguay al norte del Río Negro. Constituido como unidad político-institucional independiente en 1837, formó parte de ese norte relegado y resistió de diversas formas el centralismo montevideano. Paralelamente, y como ocurría en el resto del país, su capital "succionó toda la riqueza" y centralizó las comunicaciones así como la vida social y cultural del departamento. Según los datos del censo de 1963 vivían en el departamento 92.216 habitantes que, como en el resto del país, se distribuían desigualmente ya que más del 50\% vivía en la zona urbana (65.098 población urbana y 27.127 en las zonas rurales $)^{6}$. La concentración demográfica en la capital estaba directamente vinculada al "éxodo" de la población rural hacia las ciudades.

Salto mostró algunas peculiaridades en relación con otros departamentos del denomi-

5 La Universidad de la República, estatista y laica desde sus orígenes en 1849, detentaba el monopolio de la educación superior en el país. En 1958, el Parlamento aprobó su nuevo estatuto orgánico que le confirió una amplia autonomía política, técnica y económica. Contó a partir de entonces con total independencia del poder político central para la definición de sus lineamientos en materia educativa e institucional. Cabe señalar además, que aunque existieron planteos al respecto, en Uruguay no se establecieron nuevas instituciones de educación superior, públicas o privadas, hasta 1984 cuando un decreto de la dictadura habilitó el establecimiento de universidades privadas. Ver Decreto 343/984, 22 de agosto de 1984. Registro Nacional de Leyes y Decretos, 455.

6 Más concretamente, el total de la población urbana representaba en ese entonces el 68,75\% del departamento, concentrando la ciudad de Salto el 62,58 \%. VER Censo de población y viviendas, 1963 en http://www.ine.gub.uy/biblioteca/censos63_96/censos63_96.htm [Fecha de consulta: 14 de marzo 2013]. 
nado "interior del país", al ostentar durante el siglo XIX y las primeras décadas del XX un importante poderío económico, social y cultural que se reflejó en un desarrollo relativamente autónomo de la capital del país. Su ubicación a orillas del río Uruguay, principal vía de navegación de la zona, alentó un contacto permanente con el litoral argentino, y muy especialmente con la ciudad de Concordia ${ }^{7}$. Señala Óscar Padrón Favre que la existencia de puertos naturales en ambas ciudades generó un "efecto espejo" estimulando la conformación de "una importante red de vínculos entre ambas orillas" que se expresó en lo económico y comercial como en el plano social y cultural. ${ }^{8}$ Su intensa actividad portuaria y el espíritu empresarial de los grupos económicos y sociales locales posibilitaron su progreso material y cultural transformándose en uno de los "núcleos económica y culturalmente más dinámicos del interior del país". Esta circunstancia se vio favorecida por que contó tempranamente con buenas comunicaciones marítimas y aéreas y con un fluido tránsito fluvial que activaron los intercambios comerciales. La pujanza económica y social de la región propició, además, una rápida modernización de la ciudad que mejoró su infraestructura, y aumentó el número de sus comercios ambientando un clima general de prosperidad

La ganadería extensiva no diversificada ha sido tradicionalmente la actividad productiva del departamento por excelencia. En lo que se refiere al uso de la tierra se destaca la concentración de grandes cantidades en manos de familias, empresas, sociedades anónimas. La industria de la carne fue de gran importancia en el marco de una economía dependiente de la exportación de sus materias primas. Sin embargo, otros sectores contribuyeron a la producción del departamento como la citricultura, la horticultura y la vitivinicultura. Aún hoy la ciudad se encuentra rodeada de un cinturón de fincas dedicadas al cultivo de estos frutos y otros derivados de la horticultura. Aunque esta situación comenzó a revertirse a partir de la década del treinta con el enlentecimiento del crecimiento de la región, la ciudad continuó destacándose a nivel regional y nacional. El auge económico que experimentó el país en la década siguiente, gracias al aumento de los precios de los productos exportables y al crecimiento industrial generó un clima propicio para el desarrollo local.

La vida social y cultural de Salto se tornó muy intensa constituyéndose en el centro de una importante actividad intelectual y artística. De su seno emergieron prestigiosas

7 Ver RÍOS, Gabriel, Identidad, cultura y desarrollo en la Micro región de Frontera Salto-Concordia Tesis de Maestría en Desarrollo Regional y Local, Documento de Trabajo No 46/00, Unidad de Estudios Regionales. Facultad de Ciencias Sociales, Regional Norte, Universidad de la República, Salto - Uruguay, noviembre de 2000. Ríos analiza la conformación de la región fronteriza marcada por el Río Uruguay y los estrechos vínculos económicos, sociales y culturales que se establecieron entre ambas ciudades previo a la configuración de los Estados nacionales y que perduran hasta hoy.

8 PADRÓN FAVRE, Óscar, "Historia cultural de las regiones" en AROCENA, Felipe (coordinador) Regionalización cultural del Uruguay, Universidad de la República. Dirección Nacional de Cultura, Montevideo, 2011. p.122.

9 Ibídem. 
figuras en diversos campos: intelectuales, artistas y escritores que brindaron su aporte a las letras nacionales y también destacadas figuras del ámbito profesional y político. Para los cronistas e historiadores locales el contacto con la sociedad argentina y brasilera, la amplia distancia de Montevideo que le permitía actuar con más independencia, los inmigrantes que aportaron además de su trabajo, "la convicción de la trascendencia que tenía la cultura y la educación en la vida de los pueblos", moldearon una identidad cultural propia. ${ }^{10}$

Desde esta perspectiva la proyección de estudios universitarios en la capital salteña era una prolongación casi natural de esta particular realidad social y cultural. Si a esto se sumaba su situación geopolítica, en la frontera con el litoral argentino y lindera con casi todos los departamentos del norte del país, Salto estaba en condiciones de proyectarse hacia la región como un polo de desarrollo económico, social y cultural. Para lograrlo, amplios sectores sociales se sumaron en forma activa a distintas empresas orientadas a alcanzar el progreso de la ciudad. Se formaron, entonces, comités de apoyo en torno a reivindicaciones específicas que articularon a instituciones oficiales, entidades privadas, asociaciones profesionales, personalidades del medio, medios de prensa local, que llevaron adelante intensas campañas convocando a la movilización popular. Para mencionar algunos ejemplos: en 1942 se creó el comité que bregó por la instalación de un liceo nocturno que se concretó en 1946, también en la misma época comenzó a funcionar el Comité Popular Pro-Represa de Salto Grande que llevó a cabo una vasta movilización para concretar la construcción de una represa hidroeléctrica en ese lugar; proyecto binacional que se hizo realidad promediando la década del $70^{11}$. En forma paralela surgieron las primeras propuestas de establecer la Universidad del Norte que fueron ganando fuerza y adhesión local.

En síntesis, la creación de una universidad "propia" fue una aspiración largamente acariciada por profusos sectores de la sociedad salteña que la concibieron como otra forma de enfrentar el centralismo montevideano y un dinamizador de su propio desarrollo. Sus antecedentes se remontan a finales del siglo XIX, pero fue recién a mediados de los

10 FERNÁNDEZ SALDAÑA, José María, MIRANDA, César, Historia General de la ciudad y el Departamento del Salto, Imprenta Nacional, Montevideo, 1920, p.15.

11 En el Acta del 13 de enero de 1938, Argentina y Uruguay acordaron el común aprovechamiento hidráulico del río Uruguay (Artículo 5). Grupos locales de Concordia y Salto se organizaron, lucharon y contribuyeron a generar decisiones oficiales que terminaron en la construcción de un emprendimiento binacional: la Represa de Salto Grande. El inicio de las obras demoró más de los previsto a pesar de la movilización desplegada por el comité pro Represa de Salto Grande que concitó una amplia adhesión de la población local. Finalmente, en 1974 la Comisión Mixta ordenó el inicio de las obras en el paraje de Ayuí, a $13 \mathrm{Km}$ de Salto y a $18 \mathrm{Km}$ de Concordia. Cinco años después se terminó el gran embalse y se encendió la primera turbina. Nuevas instalaciones se fueron incorporando a la represa hasta que en 1983 y con equipamiento completo, quedó inaugurada oficialmente la represa de Salto Grande. Ver: http://www.saltogrande.org/interior.php? $\mathrm{p}=\mathrm{html} / \mathrm{menulat} /$ institucional/historia. html\&id=15, [Fecha de consulta: 17 de abril de 2013]. 
cuarenta que tomó cuerpo cuando diversas organizaciones públicas y privadas junto a las autoridades locales promovieron la creación de lo que denominaron la Universidad del Norte, iniciando gestiones ante el gobierno nacional y universitario para conseguir el apoyo político y los recursos económicos que la hicieran posible. Se destacan, en particular, dos hechos que marcaron el rumbo de este proyecto en las décadas siguientes: la colocación de la piedra fundamental de la Universidad del Norte en $1948^{12}$ y la instalación en 1957 de cursos libres de primer y segundo año de derecho y notariado de la UDELAR.

\section{La piedra fundamental de la Universidad del Norte (1948)}

La iniciativa cobró un renovado vigor en el contexto de la segunda posguerra cuando Uruguay atravesaba una relativa prosperidad económica que se revertiría en las décadas siguientes. El modelo dirigista y proteccionista impulsado por el batllismo en el gobierno posibilitaron el desarrollo industrial más importante que vivió el país. ${ }^{13}$ En ese contexto, en noviembre de 1948 durante la celebración del 75 aniversario del Instituto Politécnico Osimani y Llerena (IPOLL) ${ }^{14}$, fue colocada la piedra fundamental de la proyectada Universidad procediéndose a la posesión simbólica de los terrenos donde en un futuro se emplazarían los edificios de la sede universitaria y del nuevo liceo departamental ${ }^{15}$. Esto ocurría mientras el Parlamento uruguayo discutía la asignación de cuatro millones de pesos para la construcción de un nuevo local para el Liceo de Salto (IPOLL) ${ }^{16}$. En el acto, además de la participación de autoridades locales y nacionales, se destacó la presencia del entonces Presidente de la República Luis Batlle Berres ${ }^{17}$, amigo personal del Arq. Arman-

\section{Tribuna Salteña, Salto, 04/11/1948, p. 1.}

13 RUIZ, Esther, "El "Uruguay próspero" y su crisis. 1946-1964" en FREGA, Ana, et al., Historia del Uruguay en el siglo XX (1890-2005), EBO, Montevideo, 2007.

14 Merece una mención especial la significativa influencia del IPOLL para el desarrollo educativo y cultural del departamento al punto que de su seno partieron las iniciativas para fundar los cursos universitarios en la década del cincuenta. Fue fundado en 1873 por el Presbítero español Emiliano Pérez. Poco tiempo más tarde asumieron su dirección los profesores Gervasio Osimani y Miguel Llerena. En 1875 el Instituto, que funcionaba como internado en el cual se dictaban clases primarias y comerciales, logró que la Universidad de la República autorizara el establecimiento de cursos de preparatorios. En 1908 fue adquirido por el Estado transformándose en Liceo Departamental dependiente de la Universidad luego que, en 1912, se promulgara la Ley que estipulaba la creación de Liceos en las capitales departamentales del país.

15 La Prensa, Salto, 03/11/1948, p.1.

16 Tribuna Salteña, Salto, 27/10/1956, p.3. Finalmente el senado aprobó una partida de 1.200 .000 para erigir el nuevo edificio del IPOLL Ley $N^{o}$ 11.252. Ver http://www.parlamento.gub.uy/leyes/ AccesoTextoLey.asp?Ley=12950\&Anchor= [Fecha de consulta: 14 de marzo 2013].

17 Hicieron uso de la palabra el Ministro de Obras Públicas, Ingeniero Manuel Rodríguez Correa, 
do Barbieri, figura emblemática de Salto y futuro intendente municipal. ${ }^{18}$

En su discurso, Barbieri destacó la trascendencia del acontecimiento al que consideraba un primer jalón hacia la expansión universitaria y una conquista "frente al absolutismo absorbente de la metrópolis". ${ }^{19} \mathrm{Al}$ mismo tiempo convocó a los profesores, alumnos, exalumnos y al pueblo salteño en general a conformar un Comité Popular que presionara para que este proyecto obtuviera a la brevedad la sanción legislativa que lo hiciera realidad. ${ }^{20} \mathrm{El}$ episodio no tuvo efectos prácticos en lo inmediato, pero ubicó a la Universidad del Norte como un objetivo para amplios sectores de la comunidad salteña al tiempo que constituyó ante la opinión pública un virtual respaldo a la iniciativa por parte de los representantes del gobierno central. De alguna manera, el gesto y la presencia de las autoridades nacionales proveían de cierta legitimidad a una aspiración estrictamente local ${ }^{21}$. Se debe destacar, que hasta ese momento, el proyecto impulsado no especificaba las características, ni la orientación que debía asumir el nuevo centro de educación.

Por otra parte, el acontecimiento reavivó antiguas rivalidades locales. En la vecina ciudad de Paysandú ${ }^{22}$, en forma paralela, se estaba desarrollando un movimiento favorable a la instalación de una Facultad de Ciencias Agrarias. Esa ciudad, y el departamento, atravesaban un momento de florecimiento local producto del crecimiento de su productividad agrícola-ganadera atribuido a la subdivisión de la tierra y a fuertes inversiones nacionales y extranjeras así como al "boom industrial" que comenzó por esos años ${ }^{23}$. Este crecimiento vertiginoso, el "paymilagro" como fue denominado, fue acompañado por el sostenido aumento de su población y de un proceso de urbanización que acrecentó las aspiraciones de las elites dirigentes de convertir a la región en un núcleo de desarrollo para la zona litoral. En ese marco, en 1942, un grupo de ciudadanos con el apoyo de organizaciones de fomento y respaldados por el diario sanducero El Telégrafo se organizaron a favor de la creación de la nueva Facultad que, a diferencia de lo ocurrido en la ciudad de Salto, se plasmó en un proyecto redactado por el doctor Ricardo T. Gerona San Julián ${ }^{24}$. En 1948,

el Ministro de Instrucción Pública y Previsión Social, Óscar Secco Ellauri y el Ministro de Defensa Nacional Dr. Francisco Forteza. Se incrustó en la piedra un acta firmada por el Presidente y demás autoridades presentes.

18 Fue intendente por el período 1950-1954 y senador, representante del ala batllista del Partido Colorado durante el período 1956-1959. En 1963 integró el Consejo Departamental de Salto.

19 Ídem, p. 7.

20 Tribuna Salteña, Salto, 04/11/1948, p. 1

21 Eduardo Rodríguez Zidán, Salto y la regional Norte de la Universidad de la República, Universidad de la República. Regional Norte, Montevideo, s/f., p. 8.

22 Capital del departamento de Paysandú limítrofe, al sur, de Salto.

23 Los Departamentos. Paysandú. Editorial Nuestra Tierra, Montevideo, 1970.

24 El Comité Patriótico de Salto convocaba a las autoridades departamentales, al Magisterio, a 
unos meses antes de la colocación de la piedra fundamental de la Universidad del Norte, una nueva reunión en el Ateneo de Paysandú, que congregó a los representantes de las instituciones locales, ratificó su apoyo al mismo ${ }^{25}$. El proyecto establecía que la Facultad de Ciencias Rurales se instalaría en un predio "no menor a 1.500 hectáreas", radicado en ese departamento ${ }^{26}$. Su función principal estaría orientada a la enseñanza teórico práctica de las ciencias rurales, al desarrollo de investigaciones científicas relacionadas con dicha enseñanza y con todos los problemas que plantea la explotación técnica de la tierra así como a la divulgación en el ambiente rural, de las técnicas y métodos más adecuados y productivos de trabajo. Asimismo, estaría habilitada a otorgar títulos profesionales, dispondría de autonomía y se integraría a una futura Universidad del Litoral. Este centro educativo debía vincularse con la realidad y las necesidades económicas de la región, de ahí su énfasis en el desarrollo de las ciencias vinculadas al agro: Veterinaria y Agronomía. De esta forma se procuraba armonizar los intereses locales con los nacionales al fomentar el desarrollo del sector agropecuario; base de la economía nacional. Finalmente, ese mismo año el proyecto fue presentado al Presidente de la República que, según consignaba $E l$ Telégrafo, "lo recibió con franco entusiasmo, prometiendo prestarle la atención debida"27. En forma simultánea, el Ateneo de Paysandú realizó gestiones ante los diputados del departamento, Gabriel José D"Amado y los doctores Toribio Olaso y Héctor Payssé Reyes, para que le dieran trámite en el Parlamento naciona ${ }^{28}$. Cabe señalar, que un año después fue presentado al Consejo Central de la Universidad de la República ${ }^{29}$ y dos años más tarde el Ministerio de Instrucción Pública y Previsión Social sin que se lograra una respuesta favorable ${ }^{30}$. Se entiende, entonces, que las noticias sobre la eventual creación de la Uni-

los padres de alumnos a participar en la concentración en apoyo a la creación de la Universidad del Litoral en Paysandú a realizarse el 24 de agosto de 1942 en la sede Liceo Departamental organizada por esa institución, Nuestra Señora del Rosario, Escuela Agronómica, Escuela Industrial e Instituto Normal. El acto realizado formaba parte de los actos programados para conmemorar otro aniversario del 25 de agosto de 1825. Al finalizar el Dr. Eugenio P. Bergara, director del Liceo Departamental, leyó un acta firmada por los directores de los diversos institutos de enseñanza local que apoyaba la creación de la Universidad del Litoral. El doctor Luis Citraro, artífice principal del proyecto, formuló un discurso en el cual fundamentó la iniciativa. El Telégrafo, Paysandú, 24/08/1942, p. 1. En 1946 el Ateneo de Paysandú emitió una declaración en la cual ratificaba su apoyo a la Universidad del Litoral. En 1948 se retomó la propuesta.

25 El Telégrafo, Paysandú, 23/06/1948.

26 El Telégrafo, Paysandú, 21/06/1948, p.1.

27 El Telégrafo, Paysandú, 17/11/1948, p.3.

28 Ibídem.

29 En adelante: CDC.

30 CDC, 23 de marzo de 1949, pp. 49-50 "El Consejo resolvió recabar el pronunciamiento de las 
versidad del Norte en la vecina ciudad fueran recibidas con suspicacia y descontento ${ }^{31}$. El articulista de El Telégrafo se lamentaba que "los sanduceros, que desde hace tanto tiempo venimos realizando una insistente campaña a cielo abierto para que se cree en nuestra ciudad la Universidad del Litoral, al mismo tiempo ... ignorábamos que con mucho más secreto pero también con mucho más efectividad, aparentemente, avanzaban por el mismo camino los vecinos del Norte. ${ }^{32}$ Desde sus páginas se exigió, además, a los poderes públicos definiciones precisas en relación con los dos proyectos ya que en su visión, ambos se interferían. ${ }^{33}$ Insistía en que ese departamento presentaba las condiciones más adecuadas para la instalación del nuevo "instituto de alta enseñanza" por ser el "centro de mayor actividad y evolución agro-industrial del Litoral y el Norte, equidistante de todos los departamentos de esta región"34. Desde Salto, el diario La Prensa respondía a estas expresiones con dureza: "¿es que Paysandú pretende adjudicarse la exclusividad de las obras de importancia, de carácter nacional, a ser ejecutadas en el futuro?”. Y dando una prueba más del extendido optimismo nacional, el artículo remataba "no arrebatando, como dicen los criollos, alcanzará para todos". ${ }^{35}$

Mientras tanto, la comunidad universitaria, pese a ser interpelada por las crecientes demandas locales, se mantuvo inmersa en las discusiones sobre algunos de los postulados reformistas, muy especialmente aquellos referidos a la autonomía administrativa, pedagógica y financiera de la Universidad de la República respecto al poder político, el papel social de la institución y la participación de los estudiantes en el gobierno universitario ${ }^{36}$. Es claro que para sus autoridades la expansión geográfica no era considerada prioritaria. En todo caso, la concibieron como parte de las funciones básicas de extensión universitaria oponiéndose a la creación de nuevos centros de enseñanza superior. El entonces rector Arq. Leopoldo Agorio (1948-1956), advertía en declaraciones al diario montevideano Acción, con argumentos que El Telégrafo calificó de "típicos del conservadorismo centralista", sobre las dificultades que suponía implementar nuevos servicios universitarios debido a la carencia de recursos económicos y humanos para sostenerlos ${ }^{37}$. En la esfera estatal, más allá de declaraciones favorables y de la simpatía expresada por algunos actores políticos,

facultades de Agronomía y Veterinaria antes de tomar posición sobre tema" y CDC, 12 de diciembre de 1951, p. 379.

31 El Telégrafo, Paysandú, 04/11/1948, p. 1.

32 Ibídem.

33 Ibídem.

34 Ibídem.

35 La Prensa, Salto, 09/11/1948, p. 3.

36 MARKARIAN, Vania, JUNG, María Eugenia, WSCHEBOR, Isabel, 1958: el cogobierno autonómico, Universidad de la República, Montevideo, 2008, p. 1.

37 El Telégrafo, Paysandú,18/11/1948, p. 1. 
esta demanda no fue incorporada a la agenda pública y, por tanto, no se concretaron acciones para su implementación. No obstante, la aspiración de tener una universidad propia se mantuvo latente en los ámbitos locales.

\section{La instalación de los "cursos universitarios" de Salto y las difíciles relaciones con la Universidad de la República 1956-1957}

El asunto resurgió con renovado impulso a mediados de los cincuenta, mientras se avizoraban las primeras señales de una crisis económica, social y política provocada por el agotamiento del modelo de desarrollo aplicado en el país desde el novecientos ${ }^{38}$. Pese a ello, durante 1956, desde diversos ámbitos, convergieron planteamientos dirigidos a establecer un centro educativo público superior en la zona litoral del país. Ese año, circuló un proyecto, elaborado por el Dr. Benigno Varela Fuentes ${ }^{39}$, prestigioso médico con vasta trayectoria universitaria, que preveía el establecimiento de la "Universidad del Noroeste" que alcanzó cierta trascendencia pública, particularmente, a través de su difusión en la prensa. El planteo de Varela apuntaba a la creación de un centro de carácter regional, que trascendiera los marcos municipales, en un intento de contemplar y armonizar las aspiraciones locales. Para ello, consideraba la instalación de sedes universitarias en las distintas capitales departamentales..$^{40} \mathrm{~A}$ los argumentos expresados por los actores locales, Varela sumaba uno nuevo: las dificultades que empezaba a generar el acelerado crecimiento estudiantil que estaba experimentando la Universidad Mayor. En su opinión, esta iniciativa contribuiría a solucionar los problemas que aquejaban a esa institución a causa de la explosión de la matrícula universitaria y el déficit locativo así como de la capacidad docente para cubrir la demanda. Proponía una implementación gradual del proyecto que se complementaría con la creación de un hogar estudiantil con régimen de internado ${ }^{41}$. Ese mismo año, mientras se planificaban los festejos del bicentenario de la fundación de las ciudades de Paysandú y $\mathrm{Salto}^{42}$, la Comisión organizadora planteó que el acontecimiento brindaba una oportunidad propicia para la concreción de este anhelado proyecto. La solicitud fue acogida con be-

38 CAETANO, Gerardo y RILLA José, Historia contemporánea del Uruguay. De la colonia al Mercosur, Fin de Siglo, Montevideo, 2004, p. 205.

39 Dr. Benigno Varela Fuentes (1894-1965), médico Titular de Patología Médica de la Facultad de Medicina, creó en 1944 la cátedra de Nutrición y Digestivo. Desempeñó funciones en el Hospital Maciel y en el Hospital de Clínicas. Presidió la Sociedad de Gastroenterología del Uruguay.

40 Tribuna Salteña, Salto, 18/08/1956, p.2.y El Telégrafo, Paysandú, 13/08/1956, p. 1.

41 Tribuna Salteña, Salto, 01/08/1956, p.3.

42 Las ciudades de Salto y Paysandú fundadas en 1756 pertenecían a una misma jurisdicción correspondiente al departamento de Paysandú. En 1837 se desgajaron y pasaron a ser departamentos separados. 
neplácito por algunos miembros del Consejo Nacional de Gobierno que, no obstante ello, derivó en la consulta al Consejo Directivo Central de la Universidad de la República. Las autoridades universitarias, por su parte, negaron la petición aduciendo que la extensión de la cobertura no debía realizarse de manera improvisada, sino conforme a un plan racional y orgánico que atendiera "a las verdaderas necesidades nacionales universitarias". ${ }^{43}$ Varios consejeros universitarios afirmaron que "si se carece de rubros para la organización de sus actuales servicios, parece irrisorio que pueda planearse la estructuración de una nueva Universidad en el Litoral" ${ }^{\prime 4}$.

Paralelamente, a mediados de 1956, alumnos de bachillerato del Liceo Departamental (sección diurna y sección nocturna) con el apoyo de profesores y padres se organizaron con la finalidad de implantar los cursos de primer año de Derecho y Notariado de la Facultad de Derecho y Ciencias Sociales..$^{45}$ Luego de varias reuniones crearon el Comité Pro Cursos de Derecho que se encargó de planificar las actividades. Como en oportunidades anteriores, la iniciativa se enmarcó en un sentimiento de oposición más general, "en todos los terrenos, a la absorción masiva por la capital de las actividades del país" ${ }^{46}$. El Comité se abocó inmediatamente a establecer contactos con personalidades salteñas ${ }^{47}$ organizaciones públicas y privadas de la ciudad ${ }^{48}$, el Rotary Club, entidades bancarias de Salto y con el Consejo Departamental ${ }^{49}$. Se efectuaron también diligencias ante los representantes nacionales por el departamento ${ }^{50}$ y medios de prensa local en procura de conseguir adhesiones y ayuda económica. ${ }^{51}$ En todos los casos se obtuvieron respuestas positivas a tal iniciativa.

Alentados por esta movilización, también los estudiantes de preparatorios de ciencias económicas iniciaron gestiones similares con las autoridades de la Facultad de Ciencias Económicas que no prosperaron ${ }^{52}$. Cabe agregar, que la campaña a favor de los cursos fue simultánea a la revitalización del movimiento popular que, desde 1948, presionaba para que se concretara el proyecto argentino-uruguayo de construir la represa hidroeléctrica y

43 CDC, 14 de noviembre de 1956, p.651 y CDC 24 abril 1957, p. 201.

44 CDC, 14 de noviembre de 1956, p. 651.

45 La Prensa, Salto, 20/07/1956 y 30/07/1956. Tribuna Salteña, Salto, 17/07/1956, p. 1

46 Cassinoni, Mario A., Memoria del Rectorado, Universidad de la República, Montevideo, 1962, p. 82.

47 Tribuna Salteña, Salto, 04/08/1956, p. 1.

48 Tribuna Salteña, Salto, 11/08/1956, p. 1.

49 Tribuna Salteña, Salto, 10/08/1956, p. 4.

50 Se realizaron tratativas para lograr el apoyo del Arq. Armando Barbieri promotor Universidad del Norte en 1948 y presidente del senado en ese entonces.

51 Tribuna Salteña, Salto, 04/08/1956, 1.

52 Tribuna Salteña, Salto, 11/08/1956, p.1 y La Prensa, Salto, 10 de agosto de 1956, p.3. 
que contó con el apoyo de las fuerzas vivas departamentales como el Rotary y el Centro Comercial e Industrial. En el marco de este agitado clima, una representación de su Comité Ejecutivo visitó la capital de Paysandú con el propósito de atraer a los jóvenes de esa región a los futuros cursos universitarios y conseguir el apoyo económico de sus autoridades municipales ${ }^{53}$. En la ocasión, además, se mantuvieron contactos con las asociaciones estudiantiles, de docentes y con los profesionales de esa ciudad.

Mientras esto ocurría, y gracias a la colaboración de algunos docentes de la Facultad de Derecho y Ciencias Sociales, se hizo la solicitud correspondiente a sus autoridades y, en particular, al Decano Dr. Rodolfo Mezzera Álvarez. En la interna de la Facultad, existía un grupo de docentes, entre los que se encontraban Isaac Ganón y el Dr. Francisco del Campo (h), que inmediatamente adhirieron a la iniciativa. La propuesta, por otra parte, era compatible con el régimen de estudios libres que regía en ese centro educativo ${ }^{54}$. Del Campo consideraba que la descentralización de los cursos podía aliviar la superpoblación estudiantil que aquejaba a varios servicios universitarios, y muy especialmente a la Facultad de Derecho, que no contaban con infraestructura y recursos suficientes para absorberla. Unos años más tarde, el sociólogo Isaac Ganón destacaba los problemas generados por el desequilibrio en el acceso a la educación superior por parte de los jóvenes del interior. Las soluciones ensayadas centralmente hasta ese momento, tales como becas, préstamos a estudiantes del interior, eran meros correctivos, por lo cual, se mostró partidario de "una descentralización moderada de la Universidad, poniendo establecimientos, Facultades o Escuelas, con criterio regional, en todo el interior del país"55. Finalmente, el 18 de diciembre de 1956, el Consejo de la Facultad resolvió autorizar a sus docentes a trasladarse a Salto a dictar los cursos aunque, aclaraba, no se hacía responsable de asegurar su funcionamiento regular. En consecuencia, los gastos así como la infraestructura serían sostenidos mediante las donaciones de instituciones de fomento local y el apoyo del gobierno departamental. ${ }^{56}$

Sin embargo, el Consejo Directivo Central de la Universidad de la República se opuso desde un principio a un proyecto que no sintonizaba con la forma en que concebía la expansión de la educación superior. La presencia en el interior del país, en su visión, formaba parte de las funciones básicas de extensión universitaria manifestando fuerte reticencia a la creación de nuevos establecimientos universitarios. En oportunidades anteriores, autoridades de la Universidad habían expresado objeciones a esta iniciativa argumentando la

53 El Telégrafo, Paysandú, 11/08/1956, p. 1 Ver también La Prensa, Salto, 8 de agosto de 1956, p. 4. 54 Entrevista a Francisco del Campo (h) en Tribuna Salteña, Salto, 18/04/1957, p. 2.

55 Isaac Ganón, director del Instituto de Ciencias Sociales de esa Facultad (1958-1963) y responsable del primer censo de estudiantes que se realizó en 1960. Gaceta Universitaria, Montevideo, 27/08/1963.

56 Tribuna Salteña, Salto, 18/04/1957, 2. Ver referencia a la resolución del Consejo de Facultad de Derecho en CDC, 3 de abril de 1957, pp. 176-179. 
carencia de recursos humanos y financieros para sostenerlos ${ }^{57}$. Tras estas explicaciones subyacía el convencimiento de que el proyecto salteño reproducía el modelo de inspiración profesionalista que el reformismo cuestionaba. De hecho, la propuesta salteña, resurgía en un momento en que la comunidad universitaria se encontraba inmersa en las discusiones y luchas por la aprobación de su nuevo estatuto orgánico, ${ }^{58}$ al tiempo que intentaba dar los primeros pasos hacia una modernización académica que la transformara en un agente de cambio social fortaleciendo sus funciones de investigación, docencia y extensión para superar su tradicional orientación profesionalista. ${ }^{59}$ Este movimiento iba a tono con las ideas de circulación global y regional que consideraban a las universidades una "pieza central de los estatutos para la política nacional de ciencia" ${ }^{60}$. En esta dirección, en la mayoría de los países latinoamericanos se venía imponiendo el modelo de universidad como productora de conocimiento dando lugar a un importante movimiento de actualización científica y renovación académica. Naturalmente, como se mencionó, hubo al interior de la institución opiniones favorables a la descentralización como fue el caso de la mayoría del Consejo de la Facultad de Derecho que, en 1956, apoyó la instalación de los cursos de Salto y de algunos docentes que explícitamente expresaron su posición favorable. Pero estas posiciones resultaron minoritarias en la interna universitaria. Como consecuencia, el Consejo Directivo Central de la Universidad de la República, a iniciativa de la Federación de Estudiantes Universitarios del Uruguay ${ }^{61}$, pocos días antes de la fecha programada para su inicio, decidió la suspensión de los cursos y resolvió formar una comisión para estudiar el asunto de la Universidad del Norte.

La medida provocó de inmediato una enérgica reacción local ante las autoridades universitarias $^{62}$. El diario Tribuna Salteña, con hondo malestar, señalaba el evidente perjuicio que se ocasionaba a los estudiantes "que deberán ahora de improviso aprontar sus valijas para marcharse a la capital" y acusó a las autoridades de la Universidad de violar la autonomía técnica de la Facultad de Derecho ${ }^{63}$. Denunciaba asimismo a la FEUU, que frente al "complicado problema de la Universidad del Norte ante cuya palabra tiembla" a la vez

57 El Telégrafo, Paysandú, 18/11/1948, p. 1.

58 MARKARIAN, Vania, JUNG, María Eugenia, WSCHEBOR, Isabel, 1958: El cogobierno..., Op. Cit.

59 Ídem, pp.133-34.

60 Ver VESSURI, Hebe, "O inventamos o erramos". El Poder de la ciencia como idea-fuerza en América Latina, Buenos Aires, Universidad Nacional de Quilmes Editorial, 2007, p.194

61 En adelante: FEUU.

62 Discusión sobre la conveniencia o no de instrumentar los cursos y las distintas posiciones sobre la instalación de una universidad al norte del río Negro pueden consultarse en CDC, 3 de abril de 1957, pp.176-8 y CDC, 24 de abril de 1957, p. 200.

63 Tribuna Salteña, Salto, 07/04/1957, p. 3 
que negaba a "sus compañeros del Norte, el derecho a la cultura en su propio [lugar]"64

Paralelamente, miembros de distintas asociaciones estudiantiles de Salto conformaron un Comité de Emergencia que, en enérgica protesta, convocó a un mitin en la Plaza Artigas bajo la consigna "Abajo el Centralismo!" ${ }^{65}$. En el acto se hicieron presentes el director del liceo, miembros del gobierno departamental, padres y alumnos ${ }^{66}$. Los oradores reafirmaron la voluntad de continuar "la lucha sin descanso, por la conquista, para los departamentos de la llamada campaña, de los beneficios culturales que hoy intenta monopolizar el egoísmo y la incomprensión capitaleñas [sic]" ${ }^{97}$ El movimiento adquirió un alto contenido reivindicativo de los derechos del interior al reclamar que se "reconozca que Montevideo es la capital de la república, pero no la república." ${ }^{96}$.

La posición adoptada por la FEUU, derivó en enfrentamientos entre su dirigencia en Montevideo y los estudiantes en el interior algunas de cuyas asociaciones mantenían vínculos con esta gremial a través de la Federación de Estudiantes del Interior ${ }^{69}$. La Asociación de Estudiantes del Liceo Nocturno la acusó de desconocer la situación del interior del país y expresó su descontento ante esta actitud inconsulta ${ }^{70}$. Por su parte, en la sección diurna del liceo departamental las dos gremiales, la tradicional Asociación de Estudiantes Osimani y Llerena (AEOLL) creada en 1909 y la más reciente Asociación de Estudiantes Gustavo A. Volpe, pese a sus diferencias se unieron en la defensa de este reclamo cuestionando duramente a la federación universitaria de Montevideo. Algunos grupos, incluso, objetaron su permanencia en esta gremial y propusieron la creación una Federación de Estudiantes del Norte en defensa "de los fueros del interior". Otros, en cambio, con espíritu más conciliador, intentaron contemporizar con la dirigencia de la Federación y evitar una escisión.

Mientras tanto, el conflicto trasvasó el ámbito local y universitario y alcanzó a la Cámara de Senadores, donde el ex intendente salteño y, en ese entonces, senador Armando Barbieri formuló un alegato exigiendo la reconsideración de la medida adoptada por el CDC que cosechó algunos apoyos. ${ }^{71}$ El senador Barbieri, por su parte, apuntó sus principa-

64 Ídem, p. 7.

65 Tribuna Salteña, Salto, 14/04/1957, p. 4.

66 Tribuna Salteña, Salto, 13/04/1957, p. 4.

67 Ibídem.

68 Tribuna Salteña, Salto, 13/04/1957, p. 1.

69 Las agrupaciones estudiantiles secundarias todavía permanecían nucleadas en la FEUU. Esta situación cambiaría en la década siguiente. Todavía no disponemos de datos precisos sobre cuando se dio ese proceso de separación y cómo se fue configurando el espacio gremial estudiantil secundario en el interior y especialmente en Salto.

70 Tribuna Salteña, Salto, 10/04/1957, p. 1.

71 El Telégrafo, Paysandú, 17/04/1957, 01/04/1957 y 20/04/1957, pp. 3 y 4. 
les críticas hacia la Federación de Estudiantes por su oposición a la "extensión de la cultura" lo que consideraba una "aberración más que paradoja”. “¿Desde cuándo acá esa tercería coadyuvante de la FEUU, a favor de una iniciativa que jamás le había preocupado?"72. Acusaba, además, a la dirigencia de universitaria y particularmente al orden estudiantil de enfrentar los intereses regionalistas, instigando el celo interdepartamental para hacer fracasar el movimiento; un intento que fue bloqueado gracias al "acuerdo de voluntades de los representantes de los cinco Departamentos norteños: Salto, Paysandú, Rivera, Artigas y Tacuarembó" que resolvió "propugnar por la diversificación y polifurcación de los cursos facultativos". El presunto acuerdo proponía distribuir las carreras por departamento: Derecho, Notariado y Ciencias Económicas en Salto; Ingeniería, Agronomía y Química Industrial, en Paysandú; Medicina y Veterinaria en Rivera; Agrimensura, Estereoscopía y Fotogrametría en Artigas y Odontología y Farmacia en Tacuarembó. ${ }^{73}$ Sin embargo, este arreglo parecía no contar con unánimes apoyos. Concretamente, El Telégrafo, manifestó su "extrañeza" y desagrado frente a este "caprichoso reparto de Facultades", dejando en claro las dificultades reales de alcanzar alianzas que trascendieran los límites departamentales.

Finalmente, el gobierno de la UDELAR autorizó a los docentes de la Facultad de Derecho a impartir los cursos. La repercusión pública del hecho instó al Rector Mario A. Cassinoni a aclarar en una conferencia de prensa que "Nunca ha estado en [el] ánimo [del $\mathrm{CDC}]$ otra cosa, que evitar comprometer el prestigio de una de sus Facultades, defraudando la expectativa de los alumnos interesados y de los propios organizadores." ${ }^{\prime 4}$ Argumentó que el proceso de expansión debía concretarse por etapas considerando la posibilidad de instalar algunas Facultades en el Interior, en especial la Facultad de Agronomía. Cassinoni, como la mayoría de los consejeros universitarios, no era partidario de la duplicación de servicios y proponía instalar organismos técnicos, "escuelas apropiadas", centros de investigación, de divulgación o extensión de acuerdo a las necesidades del medio. En su opinión se corría el riesgo de fomentar disciplinas o profesiones, como era el caso de Derecho, que ya estaban suficientemente atendidas, y superpobladas, mientras se descuidaba aquellas carreras relacionadas directamente con el sector productivo y, por tanto, fundamentales para el desarrollo del país. ${ }^{75}$ Paralelamente, anunció la construcción de un Hogar Estudiantil, la apertura de un programa de becas y amplia ayuda económica dirigido a contemplar la situación de los estudiantes del interior y de escasos recursos.

En mayo de 1957, en medio de una gran expectativa de la población salteña, se inauguraron los cursos de primer año de Sociología y de Derecho Romano, dictados por los

72 Diario de Sesiones de la Cámara de Senadores de la República Oriental del Uruguay. Tomo 217, 9 de abril de 1957, pp. 242-3.

73 Ibídem.

74 CDC, 24 de abril de 1957, p. 202.

75 CASSINONI, Mario A., Memoria del Rectorado..., Op. Cit., pp. 170-1. 
profesores Dr. Isaac Ganón y Evangelio Bonilla respectivamente, ambos titulares de esas materias en Montevideo. El acontecimiento fue valorado como una gran conquista producto de la lucha de la sociedad civil salteña que sentaba las bases de "una Universidad del Norte, que no tardará en surgir, aquí o en otros departamentos, o tal vez, mejor, distribuyendo entre ellos adecuadamente sus centros de especialización". ${ }^{76}$

Las circunstancias planteadas, sin embargo, obligaron a las dirigentes de Universidad de la República a discutir la cuestión y a definir su posición frente a una eventual descentralización. La fuerte presión ejercida desde ámbitos locales fue un acicate (aunque no el único) para que su gobierno se planteara con mayor énfasis proyectar a la institución más allá de Montevideo y concretara acciones en esa dirección. En esa línea se valoraba la necesidad de ampliar su radio de acción para convertirse en una verdadera "Universidad del país". En el correr de esos años, el rector manifestó un creciente interés por entrar en contacto con la realidad del interior y con las "inquietudes y preocupaciones" de sus jóvenes "que han de ser, poco tiempo después, alumnos de la Universidad". Entendía necesario atender los reclamos locales "si se quiere en verdad ser la Universidad de la República y no solamente la Universidad de la Capital de la República". Consecuente con esta idea, realizó frecuentes viajes a localidades del interior del país donde estableció contacto con organismos culturales locales y con autoridades de otras ramas de la enseñanza. En dichas oportunidades mantuvo un fluido intercambio de opiniones con autoridades municipales, docentes y personalidades locales acerca de la descentralización de la enseñanza superior. ${ }^{77}$ Sin embargo, el proyecto de la Facultad de Agronomía de fundar una Estación Experimental de Agronomía en Paysandú iba en la línea de los planteos reformistas por lo cual contó con el apoyo decisivo del Rector Cassinoni y del Consejo Directivo Central de la Universidad de la República que aportaron recursos centrales para su instalación. Su creación formó parte de una profunda renovación de los estudios agronómicos que propició un cambio en la orientación académica de esa facultad orientado a fomentar la investigación agropecuaria como parte de la búsqueda de soluciones al estancamiento tecnológicoproductivo que afectaba al sector desde la década del treinta y agravado en los cincuenta. El 18 de julio de 1963 fue inaugurada la Estación Experimental ante la presencia de las autoridades universitarias y del Ministro de Ganadería y Agricultura, Wilson Ferreira Aldunate. La nueva repartición cubría un doble objetivo: descentralizaba la enseñanza y creaba un centro de investigación que permitiría formar técnicos en una actividad básica para la producción nacional.

Desde la perspectiva local las acciones y los tiempos de la Universidad no se adecuaban a las aspiraciones y necesidades de la población del interior. Pese a todo esto, el

76 Palabras del director del IPOLL, Dr. Domingo Iribarne. Tribuna Salteña, Salto, 08/05/1957, p. 3. 77 Ver JUNG, María Eugenia (editora), Antecedentes históricos de la Universidad en el Interior (1906-1973), Universidad de la República, Unidad de Comunicación, Montevideo, 2012. p. 21. 
episodio de los cursos de Salto dejó como saldo un asentado resentimiento local hacia la Universidad de la República debido a los vaivenes de sus autoridades que perduró en la década siguiente. La movilización local por la descentralización universitaria continuó a través de este amplio movimiento nucleado en el Comité Pro-Cursos Universitarios. Como resultado de sus gestiones en 1960, el Consejero de Gobierno Eduardo Víctor Haedo reclamó en el Consejo Nacional de Gobierno que se analizara "la forma de resolver en términos definitivos la normalización de estos cursos" $" 78$. Sin embargo, la solicitud de Haedo fue elevada al Consejo de la Facultad de Derecho y al Consejo Directivo Central de la Universidad de la República que a su vez derivó la consulta a la Asamblea General del Claustro. Asimismo, en diciembre de 1961 la Ley de Rendición de Cuentas del Estado nacional otorgó un subsidio a los cursos universitarios de Salto ${ }^{79}$. A partir de entonces ese Ministerio otorgó un aporte mensual para la subvención de algunos gastos (pasajes y estadía de docentes, compra de libros y materiales de biblioteca, servicio administrativo y de limpieza).

Los cursos universitarios continuaron funcionando y el Comité, además de ocuparse de su organización, reclamó ante las autoridades universitarias y gubernamentales su oficialización en el marco de la Universidad de la República, la que se concretó recién en 1970. Mientras tanto, durante la década de los sesenta, la idea de crear una Universidad del Norte se mantuvo en el ambiente salteño así como en otras localidades del norte uruguayo. En Tacuarembó, en diciembre de 1963, el diputado herrerista José Pedro Lamek presentó un proyecto de ley que proponía la creación de una Universidad del Norte con sede en esa ciudad. En el correr de esos años circularon otras iniciativas similares: en 1964 el diputado por Paysandú, José Cerchiaro San Juan, propuso a la Cámara de Diputados la creación de la Universidad del Litoral retomando la propuesta elaborada a fines de los 40, en 1966 el diputado de Salto Martín Boada Pettiati presentó el proyecto de ley de Creación de la Universidad del Norte en Salto y en 1969 el Intendente de Treinta y Tres realizaba gestiones con ese fin ante el Ministerio de Educación y Cultura ${ }^{80}$.

78 Actas del Consejo Nacional de Gobierno, № 185, 2 de agosto de 1960.

79 “Auméntase en \$ 50.000.00 anuales el Rubro 6.04 "Subsidios y Contribuciones" del Item 6.01 Ministerio de Instrucción Pública y Previsión Social (Secretaría) para subvención de los Cursos Universitarios de Salto.", Artículo 238 Ley no. 13.032, 7 de diciembre de 1961. Ver http://www. parlamento.gub.uy/leyes/AccesoTextoLey.asp?Ley=13032\&Anchor= [Consulta: 14 de marzo 2013].

80 Diario de sesiones de la Cámara de Representantes, 4 de diciembre de 1963, p. 91, 2 de julio de 1964, no. 992, tomo 565, pp.377-8 y 17 de agosto de 1966, pp.194-200. Ver Expediente no 427, Caja 47, 23 de junio de 1969, en Archivo General de la Nación, Montevideo. 


\section{La fundación del Movimiento Pro Universidad del Norte y la ofensiva de las derechas. 1968-1984}

A fines de los sesenta, mientras Uruguay atravesaba una grave crisis económica, social y política, y en el marco de las discusiones entre el Poder Ejecutivo y la Universidad de la República sobre el futuro de la educación superior, un grupo de personalidades e instituciones públicas y privadas de la ciudad de Salto fundaron el Movimiento pro Universidad del Norte con el propósito de promover la instalación en esa zona del país de una universidad alternativa a la de Montevideo ${ }^{81}$. El movimiento desplegó una intensa movilización de proyecciones regionales y nacionales al punto que obtuvo un fuerte respaldo del gobierno autoritario de Jorge Pacheco Areco. De hecho, su aparición pública ocurría en el momento de mayor tensión entre las autoridades universitarias y el gobierno nacional a causa de los graves sucesos acaecidos contra esa casa de estudios: violentos allanamientos policiales a sus locales, pedidos por parte del Poder Ejecutivo al Senado para destituir al Consejo Directivo Central de la Universidad de la República y primeros estudiantes asesinados en manifestaciones callejeras. En ese marco esta organización, que retomaba una antigua aspiración salteña en la que habían confluido diversos sectores sociales y políticos, fue virando hacia las vertientes más radicales de la derecha política de la época. Se produjo, entonces, una división en la comunidad salteña entre quienes apoyaban la descentralización bajo la órbita de la Universidad de la República y aquellos que en cambio buscaban un camino alternativo que "nada tiene que ver con esta ola subversiva, que nace de un sentimiento autonómico real". 82

El Movimiento Pro Universidad del Norte se presentó públicamente como un movimiento plural integrado por personas de diferentes tendencias políticas, religiosas y filosóficas que re-actualizaba una corriente tradicional en el departamento que perseguía la descentralización de la cultura y la "apoliticidad" en la enseñanza ${ }^{83}$. Para ello proponía fundar una universidad independiente y alternativa a la central ${ }^{84}$, la cual se concebía como un proyecto contrapuesto tanto en sus contenidos académicos como en su orientación político-ideológica. Desde entonces el movimiento desplegó una intensa actividad en busca de apoyos entre las "fuerzas vivas" del departamento, las autoridades municipales y nacio-

81 La ciudad de Salto es la capital del departamento homónimo ubicado en la zona litoral de Uruguay, al norte del Río Negro, a una distancia de 497 kilómetros de Montevideo.

82 Declaraciones de la Dra. Alda Thevenet de Andreu, Tribuna Salteña, Salto, 03/08/1969, pp. 5-7.

83 Tribuna Salteña, Salto, 03/08/1969, pp. 5 y 7.

84 En la misma línea surgió un movimiento en 1960 que promovió la creación de universidades libres. Sobre la base de un proyecto elaborado, entre otros por, el Dr. Aparicio Méndez el Consejero Nacional Eduardo V. Haedo presentó ante el Consejo Nacional de Gobierno un proyecto de ley que preveía la habilitación de universidades privadas en Uruguay. 
nales. Como resultado, obtuvo la adhesión de las "fuerzas vivas" del departamento (Club de Leones de Salto, el Rotary Club, el Centro Comercial e Industrial), de corporaciones profesionales como el Centro Agronómico así como de dirigentes locales y representantes del gobierno departamental vinculados a los sectores conservadores de los partidos tradicionales. Asimismo, algunos de sus miembros más destacados estaban presumiblemente vinculados a la derecha católica de Salto. En el ámbito estudiantil, en un contexto de disputa al interior de las agremiaciones, miembros de la Asociación de Estudiantes del Liceo Osimani y Llerena crearon la Juventud Salteña de Pie, organización anticomunista que dedicó su esfuerzo militante a favor de la Universidad del Norte y que confluyó en la creación, en agosto de 1970 en Salto, de la Juventud Uruguaya de Pie ${ }^{85}$.

A nivel nacional recogió la adhesión de diversos actores políticos y órganos de prensa ligados a los grupos conservadores y obtuvo el respaldo del gobierno autoritario de Jorge Pacheco Areco. En ese plano quienes promovieron esta opción sostuvieron la necesidad de contemplar "otro escenario geográfico que la Universidad de Montevideo ignora", ${ }^{86}$ aludiendo al divorcio existente entre la capital, que concentraba casi la mitad de la población del país y constituía el centro político, comercial y cultural, y el interior, donde se hallaba la fuente principal de la riqueza nacional. Alarmados porque en los centros universitarios se incitaba a la "agitación social" y se suscribía a "dogmas políticos nacionales o extranjeros" ${ }^{\$ 7}$ vislumbraron una oportunidad para contrarrestar sus adversos efectos mediante la creación de una institución independiente de la "Universidad Central" y alejada de "la utopía del "co-gobierno estudiantil" que al fin se transforma en "dictadura estudiantil". ${ }^{88}$ Estos argumentos fueron reforzados por el grupo de docentes y egresados pertenecientes a la agrupación universitaria demócrata que el reformismo había desplazado de los órganos de conducción universitaria.$^{89}$ De esta manera, la fundación de una universidad pública en Salto abría la posibilidad de imponer un formato diferente en oposición al modelo político y académico-institucional de la Universidad de la República.

A partir de la creación del Movimiento, la demanda de extender la cobertura de la educación superior trasvasó lo local incorporándose a las discusiones político-ideológicas que marcaron la agenda de esos años a nivel nacional y pasó a formar parte de las disputas por el control de la educación. Al mismo tiempo, reactualizó antiguas discusiones sobre el

85 Tribuna Salteña, Salto, 03/08/1969, pp. 5 y 7.

86 La Mañana, Montevideo, 12/06/1969, p. 5.

87 La Mañana, Montevideo, 29/05/1969, p. 5.

88 La Mañana, edición del Interior, Montevideo, 12/06/1969, pp.12-13.

89 "Universidad del Norte: necesidad impostergable", La Mañana, Monetevideo, 12/06/1969, pp. 12-13. Entrevista al Arquitecto Juan Ramón Menchaca (miembro del Consejo de Facultad de Arquitectura) y al Dr. Ricardo Yanicelli, (especialista en cirugía infantil y consejero de la Facultad de Medicina) en La Mañana, Montevideo, 22/05/1969, pp. 12-13. 
papel de las universidades y los distintos "modelos" de educación superior de importante difusión regional y mundial. Esos años estuvieron signados por el apogeo de los debates de carácter global y latinoamericano sobre el papel específico de las universidades en los procesos de institucionalización de la ciencia y la tecnología como parte de las búsquedas de un camino al desarrollo nacional. El "desarrollismo" y las teorías de la modernización ejercieron una fuerte influencia sobre estos asuntos que concitaron gran atención en la región y en el país. Los acontecimientos internacionales de comienzos de la década del sesenta vigorizaron la atracción "por las cuestiones del desarrollo"; entre ellas la Revolución cubana, y su pronta incorporación al campo socialista así como el programa de ayuda norteamericano impulsado por el presidente J.F. Kennedy conocido como "Alianza para el progreso" cuyo objetivo era estimular un plan de reformas económicas y sociales orientadas a superar el subdesarrollo y la miseria social para evitar una expansión revolucionaria a la cubana ${ }^{90}$. En ese marco, como señalan María Caldelari y Patricia Funes, "la tríada educación-técnica-ciencia" se convirtió en "un indicador del desarrollo alcanzado y de la distancia que nos separaba de los países del primer Mundo" ambientando un importante movimiento de actualización científica y renovación académica en la región ${ }^{91}$. En Uruguay, por ese entonces los actores universitarios también se encontraban discutiendo sobre la necesidad de avanzar en una reestructura académica que posibilitara la construcción de una "Universidad Nueva" cuya máxima expresión fue el plan de reforma de la Universidad formulado en 1967 por el rector Óscar Maggiolo y que constituyó el primer proyecto sistematizado de reconversión integral de la institución ${ }^{92}$. El Estado no permaneció al margen de estas discusiones. Desde principios de la década el gobierno central, interesado en acceder a las ayudas externas prometidas a través de la Alianza para el Progreso, manifestó una creciente preocupación por reestructurar el sistema educativo en el país al mismo tiempo que emprendía acciones en áreas que hasta el momento habían estado reservadas a

90 ALTAMIRANO, Carlos, "Desarrollo y Desarrollistas" en Prismas, Revista de historia intelectual, 1998, $\mathrm{N}^{\circ}$ 2, p. 79.

91 Ver CALDELARI, María y FUNES, Patricia, "La Universidad de Buenos Aires, 1955-1966: lecturas de un recuerdo" en OTEIZA, Enrique (coordinador), Cultura y Política en los años 60, Oficina de Publicaciones del CBC, Buenos Aires, 1997, p. 20; VESSURI, Hebe. O inventamos o erramos". El Poder de la ciencia como idea-fuerza en América Latina, Universidad Nacional de Quilmes Editorial, Buenos Aires, 2007, p. 210 y "Universidad e investigación científica después de las Reformas" en Educación Superior y Sociedad, 1998, V. 9, № 1, pp. 77-100.

92 Plan de Reestructuración de la Universidad de Oscar Maggiolo, Universidad de la República Montevideo, 1986; MARKARIAN, Vania, JUNG , María Eugenia, WSCHEBOR, Isabel, 1968: la insurgencia estudiantil, Universidad de la República, Montevideo, 2008 y MARKARIAN, Vania. "Apogeo y crisis del reformismo universitario. Algunos debates en torno al "Plan Maggiolo" en la Udelar" en Pensamiento Universitario, octubre, 2011, $\mathrm{N}^{\circ} 14$. 
la Universidad de la República, entrando en colisión con sus autoridades.${ }^{93}$ En el ambiente general de confrontación que vivía el país, las distintas visiones acerca de la configuración de la educación superior y de sus funciones fueron planteadas por los diferentes actores, de izquierda o de derecha, en términos dicotómicos.

Con el advenimiento del golpe de Estado en junio de 1973, y posteriormente de la intervención de la Universidad, las discusiones así como los intentos de crear otra universidad en el interior quedaron en un compás de espera. Unos meses después, representantes del Movimiento reanudaron las gestiones ante el Ministro de Cultura, Edmundo Narancio, con el propósito de concretar la ansiada universidad en Salto. Sin embargo, se acordó re-abrir la Casa de la Universidad que funcionaba en la ciudad desde 1970 donde se instalaron, en 1975, cursos universitarios de arquitectura, ingeniería, veterinaria y agronomía. El Movimiento continuó durante esos años al frente de las actividades que se desarrollaron en la Casa así como de los cursos que se dictaban. En agosto de 1984, cuando ya se vislumbraba claramente el fin del régimen, las autoridades de facto decretaron el cese de la intervención y un día después emitieron el decreto que habilitaba la creación de universidades privadas. Como consecuencia comenzó a funcionar la Universidad Católica Dámaso Antonio Larrañaga (UCUDAL) que abrió el camino para la creación del sistema universitario privado en el país. Tras la reinstalación de las autoridades legítimas de la Universidad de la República el Movimiento se transformó en Fundación Universitaria Regional Norte con el cometido de contribuir al desarrollo de las actividades universitarias en Salto. La Universidad del Norte no fue creada y en cambio, bajo la órbita de la Universidad de la República, se fundó la Regional Norte con sede en Salto cuyo estatuto fue aprobado en 1987 y que funciona hasta hoy.

\section{Conclusiones}

El presente artículo intenta demostrar la relevancia de diversos actores sociales locales en la conformación de un amplio movimiento social en Salto que propugnó la extensión de la cobertura universitaria. Se demuestra la persistencia de esos reclamos en el correr del tiempo y la presión que esos actores ejercieron sobre el gobierno central y la Universidad

93 Así lo evidencian las discusiones acerca de la propuesta realizada en 1954, a pedido del gobierno uruguayo, por la Fundación Armour del Instituto de Tecnología de Illinois de crear un centro de "investigación y desarrollo industrial", el proyecto para establecer un Centro Nacional de Investigaciones a fines de los cincuenta que finalmente no prosperó y la creación en 1961 del Consejo Nacional de Investigaciones. Ver JUNG, María Eugenia, La Udelar y la creación del CONICYT: Debates y conflictos (1961-1964), ponencia presentada al Seminario "Ciencia, educación y desarrollo", organizado por el Archivo General de la Universidad y el Departamento de Ciencias de la Educación/FHCE, 5 de julio de 2012. MARKARIAN, Vania (editora) Don Julio: Documentos del Archivo Ricaldoni, Archivo General de la Universidad de la República, Montevideo, 2007. 
de la República en pos de concretar su objetivo así como sus límites de acción. Durante el período analizado, la creación de nuevas universidades no logró incorporarse a la agenda de discusión pública ni fue visualizada como un mecanismo para resolver los problemas que afectaban a la educación superior. Tampoco los partidos políticos funcionaron como mediadores de los intereses de aquellos grupos regionales y locales que intentaron instalar esa demanda en la esfera estatal. De hecho, los diferentes proyectos que se presentaron al Parlamento nacional desde comienzos de los sesenta fueron derivados a comisiones parlamentarias, donde quedaron archivados sin ser discutidos.

Sin embargo, los reclamos descentralizadores locales influyeron en el seno de la comunidad universitaria y condicionaron a sus autoridades a implementar líneas de acción que los contemplaran. El resultado fue el incremento, en muchos casos de manera errática, de la presencia de la UDELAR en diferentes localidades del interior. De hecho, a lo largo de estos años se fueron configurando dos modelos de desarrollo universitario hacia el interior que han marcado el proceso desentralizador hasta el presente: el de Paysandú y el de Salto. El primero surgió a fines de los cincuenta en el seno de la Universidad como parte de la reestructura académica de la Facultad de Agronomía y contó con el apoyo del Rector Mario A. Cassinoni. El modelo de la Estación Experimental Mario A. Cassinoni coligó enseñanza con desarrollo de la investigación científica al mismo tiempo que incorporaba la extensión universitaria a los fines de la Estación creando un servicio específico para atenderla. En consonancia con los objetivos planteados se apostó a la radicación de los docentes con dedicación exclusiva y sólida formación académica. Para los sectores reformistas de la Universidad, esta experiencia lograba poner en práctica algunas de las propuestas de cambio estructural y académico que se estaban intentando llevar a cabo en esos años. En el caso de Salto, en cambio, la iniciativa surgió por fuera de los ámbitos universitarios donde jugó un papel decisivo la sociedad salteña cuyo interés primordial era la instalación en esa ciudad de servicios universitarios permanentes similares a los que se impartían en Montevideo. Desde la instalación de los cursos universitarios en 1956 se reclamó en forma sistemática su oficialización primero y el aumento de la oferta universitaria más tarde.

Con la creación, en 1968, del Movimiento Pro Universidad del Norte, diversos grupos alineados a la derecha política en Uruguay, en un contexto de extrema radicalización política y disputa por el control de la educación, reconvirtieron una demanda originalmente de carácter local en una reivindicación propia al tiempo que se incorporaron a los debates sobre la modernización universitaria para el desarrollo nacional. Preocupados por el sesgo ideológico de la Universidad de la República, y su incorporación a un movimiento que requirió cambios sociales más o menos radicales, este proyecto ofreció la posibilidad de establecer un formato universitario alternativo y opuesto en lo académico y en lo político. El apoyo que la solicitud recibió de diversos sectores políticos, y en particular del gobierno central, posibilitó que el tema trascendiera los estrechos marcos locales y se incorporara a la agenda política nacional en un contexto latinoamericano de debates sobre el rol de las universidades en los procesos de modernización económica y social. Las disputas locales 
en torno a las funciones de la universidad no fueron ajenas a la situación de los sistemas universitarios en los países latinoamericanos y en el mundo que, desde mediados de los cincuenta, asistieron a un incremento exponencial del número de estudiantes matriculados y a una inédita diversificación y diferenciación institucional.

El régimen autoritario instalado en junio de 1973 intervino la Universidad y postergó el proyecto de crear la Universidad del Norte. En cambio, tras las gestiones del Movimiento pro Universidad del Norte, a partir de 1975 se instalaron cursos universitarios de las facultades de Agronomía, Veterinaria, Ingeniería y Arquitectura. La intervención de la casa mayor de estudios parece haber sido suficiente para algunos de los grupos que habían apoyado el proyecto de crear la universidad en el interior. Sin embargo, la demanda de los actores locales por expandir la cobertura universitaria se mantuvo a través de esos años. Tras la apertura democrática, la Universidad de la República continuó aumentando en forma paulatina sus actividades en el interior del país. Pero, a partir del 2004 comenzó a desarrollar un inédito esfuerzo para extender su cobertura a todo el territorio nacional, atendiendo en muchos casos reclamos locales y sectoriales de diferentes procedencias. Este camino se profundizó a partir de 2007 cuando la conducción universitaria adoptó una serie de decisiones sobre cómo abordar el trabajo en el interior del país en el marco de un proceso de reforma general de la institución y en acuerdo con las autoridades nacionales y departamentales. A partir de ese momento se ha ido incrementando la presencia universitaria en las distintas localidades: año a año se abren nuevas sedes a la vez que crece exponencialmente la oferta educativa terciaria.

Recibido: 05/05/2013

Aceptado: 20/08/2013 